\title{
Breech Presentation: Vaginal Versus Cesarean Delivery, Which Intervention Leads to the Best Outcomes?
}

\author{
Apresentação Pélvica: Parto Vaginal Versus Cesariana, \\ Qual a Melhor Intervenção?
}

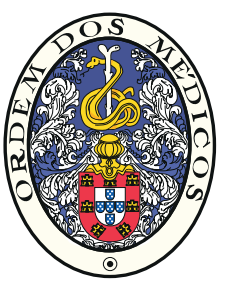

Andreia FONSECA $\square^{1}$, Rita SILVA ${ }^{1}$, Inês RATO ${ }^{1}$, Ana Raquel NEVES ${ }^{2}$, Carla PEIXOTO ${ }^{3}$, Zita FERRAZ ${ }^{4}$, Inês RAMALHO ${ }^{4}$, Ana CAROCHA ${ }^{5}$, Nina FÉLIX ${ }^{5}$, Sandra VALDOLEIROS ${ }^{5}$, Ana GALVÃO ${ }^{6}$, Daniela GONÇALVES ${ }^{6}$, Joana CURADO ${ }^{7}$, Maria João PALMA ${ }^{7}$, Isabel Lobo ANTUNES ${ }^{7}$, Nuno CLODE ${ }^{1}$, Luís Mendes GRAÇA ${ }^{1}$

Acta Med Port 2017 Jun;30(6):479-484 - https://doi.org/10.20344/amp.7920

\section{ABSTRACT}

Introduction: The best route of delivery for the term breech fetus is still controversial. We aim to compare maternal and neonatal outcomes between vaginal and cesarean term breech deliveries.

Material and Methods: Multicentric retrospective cohort study of singleton term breech fetuses delivered vaginally or by elective cesarean section from January 2012 - October 2014. Primary outcomes were maternal and neonatal morbidity or mortality.

Results: Sixty five breech fetuses delivered vaginally were compared to 1262 delivered by elective cesarean. Nulliparous women were more common in the elective cesarean group $(69.3 \%$ vs $24.6 \% ; p<0.0001)$. Gestational age at birth was significantly lower in the vaginal delivery group ( $38 \pm 1$ weeks vs $39 \pm 0.8$ weeks; $p=0.0029$ ) as was birth weight (2928 $\pm 48.4 \mathrm{~g} v s 3168 \pm 11.3 \mathrm{~g} ; p<0.0001$ ). Apgar scores below seven on the first and fifth minutes were more likely in the vaginal delivery group ( 1 st $\operatorname{minute:~} 18.5 \% \mathrm{vs} 5.9 \% ; p=$ 0.0006 ; OR 3.6 [1.9 - 7.0]; $5^{\text {th }}$ minute: $3.1 \%$ vs $0.2 \% ; p=0.0133$; OR 20.0 [2.8 - 144.4]), as was fetal trauma (3.1\% vs $0.3 \%: p=0.031$; OR 9.9 [1.8-55.6]). Neither group had cases of fetal acidemia. Admission to the Neonatal Intensive Care Unit, maternal postpartum hemorrhage and the incidence of other obstetric complications were similar between groups.

Discussion: Although vaginal breech delivery was associated with lower Apgar scores and higher incidence of fetal trauma, overall rates of such events were low. Admission to the neonatal intensive care unit and maternal outcomes were similar.

Conclusion: Both delivery routes seem equally valid, neither posing high maternal or neonatal complications' incidence.

Keywords: Breech Presentation; Cesarean Section; Delivery, Obstetric

\section{RESUMO}

Introdução: A melhor via de parto do feto pélvico de termo ainda é controversa. Pretendemos comparar desfechos maternos e neonatais entre partos vaginais e cesarianas de fetos pélvicos de termo.

Material e Métodos: Estudo de coorte, multicêntrico e retrospetivo, incluindo gestações de feto único de termo, em apresentação pélvica, que terminaram em parto vaginal ou cesariana eletiva entre janeiro de 2012 e outubro de 2014. Os desfechos primários foram a morbilidade e mortalidade maternas e neonatais.

Resultados: Sessenta e cinco partos vaginais foram comparados com 1262 cesarianas eletivas. As nulíparas foram mais frequentes no grupo das cesarianas $(69,3 \%$ vs $24,6 \% ; p<0,0001)$. A idade gestacional foi inferior nos partos vaginais $(38 \pm 1$ semanas vs $39 \pm 0,8$ semanas; $p=0,0029)$, verificando-se o mesmo para o peso ao nascer $(2928 \pm 48,4 \mathrm{~g} v s 3168 \pm 11,3 \mathrm{~g} ; p<0,0001)$. Índices de Apgar $<7$ foram mais frequentes nos partos vaginais ( $1^{\circ}$ minuto: $18,5 \%$ vs $5,9 \% ; p=0,0006$; OR 3,6 [1,9 - 7,0]; $5^{\circ}$ minuto: $3,1 \%$ vs $0,2 \%$; $p=0,0133$; OR 20,0 [2,8 - 144,4]). Verificou-se também uma maior incidência de traumatismo fetal neste grupo $(3,1 \%$ vs $0,3 \%$; $p=0,031$; OR 9,9 [1,8 - 55,6]). Nenhum grupo teve casos de acidemia fetal. As taxas de internamento na unidade de cuidados intensivos neonatais, de hemorragia materna pós-parto ou de outras complicações obstétricas foram idênticas.

Discussão: O parto vaginal associou-se a índices de Apgar inferiores e a uma maior incidência de traumatismo fetal, com taxas globalmente baixas. Não se verificaram diferenças nas taxas de internamento neonatal nem nos desfechos maternos.

Conclusão: Ambas as vias de parto parecem adequadas, nenhuma condicionando incidências elevadas de complicações maternas ou neonatais.

Palavras-chave: Apresentação Pélvica; Cesariana; Parto Obstétrico

\section{INTRODUCTION}

Delivery of the singleton term breech fetus is still one of the most controversial subjects in modern Obstetrics. Changes in clinical practice were introduced following the publication of the Term Breech Trial, ${ }^{1-3}$ which indicated that perinatal and neonatal mortality as well as serious neonatal morbidity were increased in the group delivered vaginally,

albeit similar maternal outcomes. ${ }^{4}$ As a result, breech presentation at term became an indication for cesarean section for many. Breech presentation occurs in 3\%-4\% of all term pregnancies and, in the absence of maneuvers to decrease its prevalence, such as the external cephalic version, it is an important contributor to primary cesarean

\footnotetext{
1. Departamento de Obstetrícia e Ginecologia. Hospital de Santa Maria. Centro Hospital Lisboa Norte. Lisboa. Portugal.

2. Maternidade Bissaya Barreto. Centro Hospitalar Universitário de Coimbra. Coimbra. Portugal.

3. Departamento de Obstetrícia e Ginecologia. Centro Hospitalar de S. João. Porto. Portugal.

4. Maternidade Daniel de Matos. Centro Hospitalar Universitário de Coimbra. Coimbra. Portugal.

5. Maternidade Alfredo da Costa. Centro Hospitalar Lisboa Central. Lisboa. Portugal.

6. Maternidade Júlio Dinis. Centro Materno-Infantil do Norte. Centro Hospitalar do Porto. Porto. Portugal.

7. Departamento de Obstetrícia e Ginecologia. Hospital Garcia de Orta. Almada. Portugal.

$\square$ Autor correspondente: Andreia Fonseca. andreiafonseca4@gmail.com

Recebido: 07 de junho de 2016 - Aceite: 10 de abril de 2017 | Copyright @ Ordem dos Médicos 2017
} 
sections, increasing the likelihood of a new cesarean in future pregnancies. 5,6

However, Term Breech Trial methodology and conclusions have been questioned and other studies have shown different results. Glezerman's analysis on the Term Breech Trial study revealed serious limitations, including lack of skilled assistance and inappropriate fetal surveillance during labor as well as severe inclusion criteria infringement. ${ }^{7}$ Goffinet's prospective study (PREMODA) showed that, when cases are adequately selected and obstetricians are experienced in vaginal breech delivery, outcomes are not significantly different. ${ }^{8}$ In fact, a Norwegian study comparing planned cesarean and vaginal deliveries and including 559 breech fetuses concluded that cesarean delivery significantly increased the risk of neonatal intensive care admission and pulmonary complications. ${ }^{9}$ And concerning long term neonatal morbidity and mortality, outcomes are not affected by the mode of the delivery, as shown by the Term Breech Trial group. ${ }^{10}$

Yet the effects of the Term Breech Trial cannot be erased and if management of term breech presentation remains unchanged, new generations of obstetricians will be less qualified to deliver breech fetuses vaginally. Ultimately, this lack of expertise might lead to either complications due to poor assistance to vaginal deliveries or to the rise of cesarean section rates with uncertain effects on maternal and perinatal outcomes.

The aim of the study was to compare maternal and neonatal outcomes according to the mode of delivery of term breech fetuses in Portuguese tertiary hospitals.

\section{MATERIAL AND METHODS}

A multicentric retrospective cohort study was conducted and data was collected from seven Portuguese tertiary hospitals. Participating hospitals included Santa Maria University Hospital, Bissaya Barreto Maternity Hospital, São João Hospital Center, Daniel de Matos Maternity, Alfredo da Costa Maternity Hospital, Júlio Dinis Maternity Hospital and Garcia de Orta Hospital.

Inclusion criteria were singleton term ( $\geq 37$ weeks) breech fetuses delivered either vaginally or by planned elective cesarean section from January 2012 to October 2014. Intrapartum cesarean deliveries and elective cesarean deliveries for indications other than breech presentation were excluded.

Cases were identified using the hospitals' databases.
Then maternal and neonatal medical records were reviewed and data was obtained and inserted in a standardized data sheet.

The primary outcomes were defined as maternal and neonatal morbidity or mortality. We analyzed demographic and obstetrics characteristics, such as maternal age, ethnicity, parity, previous breech fetus, previous breech vaginal delivery and previous cesarean delivery. For the current pregnancy, variables included breech presentation type, external cephalic version trial, gestational age at delivery, and, if vaginal delivery, need for induction of labor and additional maneuvers to deliver the fetus, umbilical cord prolapse and perineal trauma. Aditional maneuvers were defined as Piper's forceps application or exceptional maneuvers, such as Dührssen's incisions, symphysiotomy and Zavanelli's maneuver. Newborn weight was also analyzed. Maternal morbidity included postpartum hemorrhage, anemia and need for blood transfusion. Neonatal morbidity included Apgar score below $7\left(1^{\text {st }}\right.$ and $5^{\text {th }}$ minutes), fetal acidemia, trauma and admission to the Neonatal Intensive Care Unit (NICU). Umbilical cord blood gas sampling was not routinely performed in any of the hospitals included. Other unspecified maternal and neonatal complications were also registered.

Fisher's exact test and $\chi^{2}$ test were used for categorical variables, while student's t-test and Mann-Whitney test were used for continuous variables. When appropriate, odds ratio $(\mathrm{OR})$ were calculated. Ninety five percent confidence intervals were used. $P$ values less than 0.05 were considered statistically significant. GraphPad Prism 6.04 was used for statistical analysis.

\section{RESULTS}

We analyzed data from 1327 deliveries, 1262 elective cesarean sections (95.1\%) and 65 vaginal deliveries (4.9\%). Demographic characteristics studied were similar in both groups (Table 1), except for parity with a significantly higher rate of nulliparous women in the cesarean delivery group (69.3\% vs $24.6 \% ; p<0.0001)$. As for multiparous women, previous breech fetus was more frequent in the cesarean delivery group ( $18.3 \%$ vs $4.1 \% ; p=0.008)$ as was previous cesarean delivery $(46.3 \%$ vs $4.1 \% ; p<0.0001)$. However, previous vaginal breech delivery was comparable among the groups $(1.0 \%$ vs $2.1 \% ; p=0.45)$.

Pregnancy and delivery data is registered in Table 2. External cephalic version trial was performed similarly in Table 1 - Demographic characteristics and previous obstetric history

\begin{tabular}{|c|c|c|c|}
\hline & $\begin{array}{c}\text { Vaginal delivery } \\
(n=65)\end{array}$ & $\begin{array}{c}\text { Cesarean delivery } \\
(n=1262)\end{array}$ & $p$ \\
\hline Maternal age (years) & $31.7 \pm 5.4$ & $31.9 \pm 5.1$ & 0.85 \\
\hline Caucasian & $46(70.8 \%)$ & $970(76.9 \%)$ & 0.29 \\
\hline Nulliparous women & $16(24.6 \%)$ & $875(69.3 \%)$ & $<0.0001$ \\
\hline Previous breech fetus* & $2(4.1 \%)$ & $71(18.3 \%)$ & 0.008 \\
\hline Previous vaginal breech* & $1(2.0 \%)$ & $4(1.0 \%)$ & 0.45 \\
\hline Previous cesarean delivery $(=1)^{*, \dagger}$ & $2(4.1 \%)$ & $179(46.3 \%)$ & $<0.0001$ \\
\hline
\end{tabular}

${ }^{*}$ Total reporting to multiparous women (49 in the vaginal delivery group and 387 in the cesarean delivery group). ${ }^{\dagger}$ Includes all previous cesarean deliveries, regardless of indication. 
both groups $(6.7 \%$ vs $10.8 \% ; p=0.21)$. All external cephalic version trials took place between the $36^{\text {th }}$ and the $37^{\text {th }}$ week of pregnancy and were performed without maternal analgesia. Salbutamol was used as a tocolytic agent for the procedure. From all women who delivered vaginally only six $(9.2 \%)$ were induced, the main indication being gestational age. Only one induction occurred at 37 weeks, after a failed external cephalic version, in a multiparous woman without previous prenatal care. Vaginal deliveries occurred earlier than cesarean deliveries ( $38 \pm 1$ weeks vs $39 \pm 0.8$ weeks; $p=0.003$ ) and newborns delivered by cesarean section had a higher birth weight $(2928 \pm 390.4 \mathrm{~g}$ vs $3168 \pm 401.9$; $p<$ $0.0001)$. There was one case of umbilical cord prolapse, successfully reduced with delivery of a newborn with an Apgar score of 8/10. Piper's forceps were used in just seven $(10.8 \%)$ of vaginal deliveries, but no other maneuvers were registered. Episiotomies were performed in $70.8 \%$ of vaginal deliveries. One woman had a third degree perineal laceration.

As for neonatal outcomes (Table 3), the group delivered vaginally had a higher incidence of Apgar scores below 7 . Umbilical cord blood gas analysis was available for only $10.8 \%$ and $10.2 \%$ of newborns delivered vaginally and by cesarean, respectively, and there were no cases of fetal acidemia among these. Two neonates were admitted to the NICU in the vaginal delivery group while 35 newborns required NICU admission in the cesarean delivery group (3.1\% vs $2.8 \% ; p=0.70$ ). NICU admission diagnoses are stated in Table 4. Congenital disease reported cases concern fetal malformation, septal defects, cytomegalovirus

Table 2 - Pregnancy and delivery characteristics

\begin{tabular}{lccc} 
& $\begin{array}{c}\text { Vaginal delivery } \\
(\mathrm{n}=65)\end{array}$ & $\begin{array}{c}\text { Cesarean delivery } \\
(\mathrm{n}=1262)\end{array}$ & $\boldsymbol{p}$ \\
\hline External cephalic version trial & $7(10.8 \%)$ & $85(6.7 \%)$ & 0.21 \\
Type of breech presentation at delivery & & & $<.0001$ \\
Frank breech & $22(20.0 \%)$ & $123(4.1 \%)$ & $52(9.7 \%)$ \\
Complete breech & $13(33.8 \%)$ & $53(4.2 \%)$ & 0.003 \\
Incomplete breech & $1(1.5 \%)$ & $1034(81.9 \%)$ & $39 \pm 0.8$ \\
Unspecified & $29(44.6 \%)$ & $3168 \pm 401.9$ & $<0.0001$ \\
Gestational age at delivery (weeks) & $38 \pm 1$ & & \\
Birth weight & $2928 \pm 390.4$ & & \\
\hline
\end{tabular}

Table 3 - Maternal and neonatal outcomes

\begin{tabular}{|c|c|c|c|c|}
\hline & $\begin{array}{l}\text { Vaginal delivery } \\
\quad(n=65)\end{array}$ & $\begin{array}{l}\text { Cesarean delivery } \\
\qquad(n=1262)\end{array}$ & OR $(95 \% \mathrm{Cl})$ & $p$ \\
\hline Apgar score $<71^{\text {st }} \min$ & $12(18.5 \%)$ & $74(5.9 \%)$ & $3.6(1.8-7.1)$ & 0.0006 \\
\hline Apgar score $<75^{\text {th }} \min$ & $2(3.1 \%)$ & $2(0.2 \%)$ & $20(2.7-144.4)$ & 0.01 \\
\hline Fetal acidemia & $0(0 \%)$ & $0(0 \%)$ & - & - \\
\hline Fetal trauma & $2(3.1 \%)$ & $4(0.3 \%)$ & $9.9(1.8-55.6)$ & 0.03 \\
\hline Neonatal Intensive Care Unit (NICU) admission & $2(3.1 \%)$ & $35(2.8 \%)$ & - & 0.70 \\
\hline Maternal postpartum hemorrhage & $0(0 \%)$ & $17(1.3 \%)$ & - & 1.00 \\
\hline Postpartum anemia (hemoglobin $<8 \mathrm{~g} / \mathrm{dL}$ ) & $0(0 \%)$ & $18(1.4 \%)$ & - & 1.00 \\
\hline Need for blood transfusion & $0(0 \%)$ & $9(0,7 \%)$ & - & 1.00 \\
\hline Other maternal complications & $1(1.5 \%)$ & $9(0.7 \%)$ & - & 0.40 \\
\hline
\end{tabular}

congenital infection, and ileal stenosis. Fetal trauma incidence was low among both groups. However traumatic events were more common in the vaginal delivery group (3.1\% vs 0.3\%; $p=0.031$; OR 9.9 [1.8 - 55.6]). Two cases of brachial plexus paralysis, one of them associated with fetal skin incision and fracture of the clavicle, were recorded in the vaginal delivery group against one iatrogenic fetal skin incision, two cases of fetal ecchymosis and hematoma, one with hip dislocation, and one iatrogenic fracture of the humerus in the cesarean delivery group. There were no cases of fetal or neonatal death in either group.

No statistically significant differences were identified concerning maternal outcomes (Table 3). Other maternal complications are detailed in Table 5.

\section{DISCUSSION}

Our study describes the outcomes of breech fetuses delivered vaginally or by elective cesarean section in nearly three years in seven Portuguese tertiary hospitals, including a very significant number of deliveries and being the first of its kind in our country.

In general, both groups were similar concerning demographic characteristics and previous obstetric history. However, a higher proportion of nulliparous women $(69.3 \%$ vs $24.6 \%$; $p<0.0001$ ) was identified in the cesarean delivery group. Such finding can be explained by a higher propensity to wish for a vaginal delivery among multiparous women and, on the obstetricians' side, a higher chance of better outcomes in a formerly tested pelvis. Breech presentation in a previous pregnancy was also more 
Table 4 - Neonatal diagnosis at admission to NICU

\begin{tabular}{|c|c|c|}
\hline & $\begin{array}{l}\text { Vaginal delivery } \\
\quad(n=65)\end{array}$ & $\begin{array}{l}\text { Cesarean delivery } \\
\quad(n=1262)\end{array}$ \\
\hline \multirow{8}{*}{$\begin{array}{l}\frac{\sigma}{0} \\
\frac{0}{0} \\
\frac{0}{\tilde{\varepsilon}} \\
\frac{0}{0} \\
\frac{\pi}{\pi} \\
\frac{0}{0} \\
\frac{0}{0} \\
\frac{0}{0} \\
\frac{\pi}{0}\end{array}$} & \multirow{4}{*}{$\begin{array}{l}\text { Low birth weight, birth } \\
\text { trauma, coagulopathy } \\
(1 ; 1.54 \%)\end{array}$} & $\begin{array}{l}\text { Congenital disease } \\
(11 ; 0.87 \%)\end{array}$ \\
\hline & & $\begin{array}{l}\text { Respiratory complications } \\
(10 ; 0.79 \%)\end{array}$ \\
\hline & & $\begin{array}{l}\text { Hyperbilirubinemia } \\
(5 ; 0.40 \%)\end{array}$ \\
\hline & & $\begin{array}{l}\text { Hypotonia } \\
(2 ; 0.16 \%)\end{array}$ \\
\hline & \multirow{4}{*}{$\begin{array}{l}\text { Hyperbilirubinemia } \\
(1 ; 1.54 \%)\end{array}$} & $\begin{array}{l}\text { Infectious complications } \\
(2 ; 0.16 \%)\end{array}$ \\
\hline & & $\begin{array}{l}\text { AB0 isoimmunization } \\
(2 ; 0.16 \%)\end{array}$ \\
\hline & & $\begin{array}{l}\text { Perinatal ischemic stroke } \\
(1 ; 0.08 \%)\end{array}$ \\
\hline & & $\begin{array}{l}\text { Neonatal tachycardia } \\
(2 ; 0.16 \%)\end{array}$ \\
\hline
\end{tabular}

common among women submitted to cesarean delivery in the current pregnancy $(18.3 \%$ vs $4.1 \% ; p=0.008)$. This is probably related to the higher rate of previous cesarean delivery among these women $(46.3 \%$ vs $4.1 \%$; $p<0.0001)$. The difference concerning the type of breech presentation at delivery is due to the lack of data in the cesarean delivery group and, under such circumstances, has very limited use.

External cephalic version is a safe procedure that can decrease the prevalence of term breech fetuses and subsequently lower the cesarean section rate. ${ }^{11,12}$ However, the small number of women who had undergone a trial of external cephalic (circa 10\% with a similar fraction on both groups) shows the low acceptance of this maneuver in the medical and pregnant population.

Although of very little clinical significance, we found gestational age at delivery to be lower for vaginal deliveries (38 \pm 1 weeks vs $39 \pm 0.8$ weeks; $p=0.003$ ), which in itself most likely explains the lower birth weight identified in the same group $(2928 \pm 390.4$ vs $3168 \pm 401.9 ; p<0.0001)$. We believe these were mere statistic findings, especially as only six women in the vaginal delivery group were induced, all after 38 weeks of gestation.

A recent meta-analysis including 27 studies and 258 953 term breech deliveries, concluded that planned vaginal delivery has a higher relative risk for adverse neonatal outcomes, but absolute risks are lower than previously reported. ${ }^{13}$ In fact, vaginal delivery can be considered a more demanding process for the fetus, depressing early-life parameters. Burgos et al found Apgar scores below 7 at the $5^{\text {th }}$ minute in $2.9 \%$ of newborns delivered vaginally and $0.4 \%$ in elective cesarean deliveries. ${ }^{12}$ Studies comparing planned modes of delivery, such as PREMODA, had similar results. ${ }^{8}$ On this subject, we found that lower Apgar scores were significantly more common among neonates delivered vaginally at $1^{\text {st }}$ and $5^{\text {th }}$ minutes (Apgar score $<718.5 \%$ vs $5.9 \%$ and $3.1 \%$ vs $0.2 \%$, respectively; $p<0.05)$. These findings represent a risk of an Apgar score below 7, 3.6 to 20 times higher for newborns delivered vaginally.
Table 5 - Other maternal complications

\begin{tabular}{|c|c|c|}
\hline & $\begin{array}{l}\text { Vaginal delivery } \\
\quad(n=65)\end{array}$ & $\begin{array}{l}\text { Cesarean delivery } \\
\quad(n=1262)\end{array}$ \\
\hline \multirow{4}{*}{ 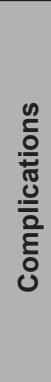 } & \multirow{4}{*}{$\begin{array}{l}\text { Retained placenta } \\
(1 ; 1.54 \%)\end{array}$} & $\begin{array}{l}\text { Infectious complications } \\
(6 ; 0.48 \%)\end{array}$ \\
\hline & & $\begin{array}{l}\text { Uterine atony } \\
(1 ; 0.08 \%)\end{array}$ \\
\hline & & $\begin{array}{l}\text { Retained placenta } \\
(1 ; 0.08 \%)\end{array}$ \\
\hline & & $\begin{array}{l}\text { Broad ligament laceration } \\
\text { with intraoperative major } \\
\text { hemorrhage } \\
(1 ; 0.08 \%)\end{array}$ \\
\hline
\end{tabular}

Our results regarding fetal trauma showed a 9.9 increased risk of injury $(3.1 \%$ vs $0.3 \% ; p=0.031)$ for vaginally delivered infants, yet overall rates reveal a low incidence of traumatic events. Previously published studies have reported similar results..$^{4,8}$ Indeed, the PREMODA prospective study described $1.80 \%$ fetal injury in the planned vaginal delivery group and $0.46 \%$ in the planned cesarean deliveries. Traumatic events most frequently involved brachial plexus injuries, clavicle fractures and hematomas, which is in agreement with our results. Yet evaluation of fetal trauma should take into account the severity and prognosis of such injuries, both often disregarded. Comparable NICU admission rates were found. As for fetal trauma, we believe this analysis should consider only diagnosis likely to be a consequence of the chosen mode of delivery. However, most of them are of multifactorial origin.

In this study, no cases of fetal or neonatal death were identified. In Portugal, vaginal breech deliveries require the presence of a skilled obstetrician. Such requirement, along with fetal and maternal cautious monitoring during labor and the frequent proper selection of candidates for vaginal delivery could have had a strong influence on the mortality rate. Due to the lack of proper prospective studies, selection criteria are mostly based on clinical experience and tend to include frank or complete breech presentation, adequate maternal pelvis, absence of fetal head hyperextension and an estimated fetal weight between 2500 and 4000 g. ${ }^{14,15}$

Although Obstetrics involves the simultaneous care of two different patients, the fetus and the pregnant woman, most studies concerning term breech delivery tend to focus on perinatal outcomes. However, a Canadian study evaluating maternal outcomes compared serious maternal morbidity and mortality between elective cesarean sections for breech presentation and vaginal deliveries, regardless of fetal presentation, and concluded that risks of severe maternal morbidity were higher for planned cesareans, with three times the risk of major infection. ${ }^{14}$ Alternatively, if one considers long-term outcomes, several studies have reported cesarean delivery as a protective factor for stress urinary incontinence and pelvic organ prolapse..$^{17,18}$ Concerning short-term maternal impact of the chosen route of delivery, our study shows lack of statistically significant difference. The same findings were described by the Term Breech Trial. ${ }^{4}$ A prospective Norwegian study quantified a 
significantly higher volume of blood lost during cesarean delivery, when compared to breech vaginal delivery (435 \pm $317 \mathrm{~mL}$ vs $359 \mathrm{~mL} \pm 231 \mathrm{~mL}) .{ }^{15}$ In fact, our study reports postpartum hemorrhage and anemia exclusively after cesarean deliveries. Two years after the Term Breech Trial, the same group analyzed maternal outcomes, reporting only an increased incidence of constipation in the planned cesarean group (27.2\% vs $20.2 \%) .{ }^{16}$ Still, long-term maternal and obstetric complications need to be properly assessed, particularly regarding pregnancies after cesarean delivery.

The present study is the first Portuguese project comparing vaginal delivery and elective cesarean for singleton breech fetuses. The study period started after the publication of the Term Breech Trial and breech presentation management did not change significantly between 2012 and 2014 in our country. Planned mode of the delivery was not taken into account and all cases were analyzed according to the actual mode of delivery, allowing for more clinically relevant results. Exclusion of indications for cesarean delivery other than breech presentation limited bias and confounding factors. We believe the exclusion of cesarean deliveries for dystocia, suspected fetal distress and other maternal or fetal indications to be one of the primary strengths of our study.

Our study presents several limitations, starting with its retrospective design. Data was collected from clinical files and was, therefore, limited to the observations registered. In order to minimize transcription and interpretation errors, a single database with instructions was created and sent to the resident in charge of data collection at each hospital. Lack of data concerning important outcomes might have compromised our results. For example, only $10 \%$ from each group had data regarding umbilical blood cord analysis and the decision to sample cord blood was the team's prerogative, which wasn't consistent with any identifiable criteria, such as a lower Apgar score. Moreover, deliveries took place in different hospitals and, even in the same delivery ward, management might have varied slightly depending on the team involved.

\section{CONCLUSION}

In this study, vaginal breech delivery was associated with lower Apgar scores and with a low incidence of fetal trauma albeit higher than the observed with cesarean delivery. However, neonatal admission to the NICU and maternal outcomes were similar. From our standpoint, both delivery routes seem equally valid, requiring further evaluation, particularly of sequelae resulting from trauma. Yet we found low incidence of both maternal and neonatal complications regardless of the mode of delivery.

In this ever contemporary discussion, more studies are required to properly assess which intervention is best, particularly regarding long term outcomes. Routine use of decision protocols for proper selection of vaginal delivery candidates, including maternal and fetal measurements, has proven to be beneficial, resulting in an increase in vaginal delivery rates without compromising neonatal outcomes ${ }^{17}$. On that account, accurate selection criteria need to be identified in order to adequately counsel each woman on the best route of delivery. While prospective randomized studies with strict protocols and selection criteria would be of superior evidence, the relatively low prevalence of term breech presentation and the shadow previously cast by other publications make such projects hard to implement. Thus, future data will most likely come from retrospective or prospective observational study protocols.

\section{PROTECTION OF HUMANS AND ANIMALS}

This study was conducted in accordance with the principles of the Declaration of Helsinki, ICH Guidelines for Good Clinical Practice and in full conformity with relevant regulations. Patients provided written informed consent for study participation. The study protocol was approved by the local ethics committee.

\section{DATA CONFIDENTIALITY}

The authors declare having followed the protocols in use at their working center regarding patients' data publication.

\section{CONFLICTS OF INTEREST}

All authors report no conflict of interest.

\section{FUNDING SOURCES}

No funding or grant was received for this manuscript.

\section{REFERENCES}

1. Rietberg CC, Elferink-Stinkens PM, Visser HA. The effect of the Term Breech Trial on medical intervention behaviour and neonatal outcome in The Netherlands: an analysis of 35, 453 term breech infants. BJOG. 2005;112:205-9.

2. Hartnack Tharin JE, Rasmussen S, Krebs L. Consequences of the term breech trial in Denmark. Acta Obstet Gynecol Scand. 2011;90:767-71.

3. Daviss BA, Johnson KC, Lalonde AB. Evolving evidence since the term breech trial: Canadian response, European dissent, and potential solutions. J Obstet Gynaecol Can. 2010;32:217-24.

4. Hannah ME, Hannah WJ, Hewson SA, Hodnett ED, Saigal S, Willan AR. Planned caesarean section versus planned vaginal birth for breech presentation at term: a randomised multicentre trial. Term Breech Trial Collaborative Group. Lancet. 2000;356:1375-83.

5. Hickok DE, Gordon DC, Milberg JA, Williams MA, Daling JR. The frequency of breech presentation by gestational age at birth: a large population-based study. Am J Obstet Gynecol. 1992;166:851-2.

6. Joseph KS, Young DC, Dodds L, O'Connell CM, Allen VM, Chandra S, et al. Changes in maternal characteristics and obstetric practice and recent increases in primary cesarean delivery. Obstet Gynecol. 2003;102:791800.

7. Glezerman M. Five years to the term breech trial: The rise and fall of a randomized controlled trial. Am J Obstet Gynecol. 2006;194:20-5.

8. Goffinet F, Carayol M, Foidart JM, Alexander S, Uzan S, Subtil D, et al. Is planned vaginal delivery for breech presentation at term still an option? Results of an observational prospective survey in France and Belgium. Am J Obstet Gynecol. 2006;194:1002-11.

9. Kolås T, Saugstad OD, Daltveit AK, Nilsen ST, Øian P. Planned cesarean versus planned vaginal delivery at term: Comparison of newborn infant outcomes. Am J Obstet Gynecol. 2006;195:1538-43.

10. Whyte H, Hannah ME, Saigal S, Hannah WJ, Hewson S, Amankwah K, et al. Outcomes of children at 2 years after planned cesarean birth versus planned vaginal birth for breech presentation at term: The international 
randomized Term Breech Trial. Am J Obstet Gynecol. 2004;191:864-71.

11. Hofmeyr GJ, Kulier R, West HM. External cephalic version for breech presentation at term. Cochrane Database Syst Rev. 2015;4:CD000083.

12. Burgos J, Rodríguez L, Cobos P, Osuna C, Del Mar Centeno M, Larrieta $\mathrm{R}$, et al. Management of breech presentation at term: a retrospective cohort study of 10 years of experience. J Perinatol. 2015;35:803-8.

13. Berhan $Y$, Haileamlak $A$. The risks of planned vaginal breech delivery versus planned caesarean section for term breech birth: A meta-analysis including observational studies. BJOG. 2016;123:49-57.

14. Kotaska A, Menticoglou S, Gagnon R, Farine D, Basso M, Bos H, et al. Vaginal delivery of breech presentation. J Obs Gynaecol Can. 2009;31:557-66.

15. ACOG Committee on Obstetric Practice. ACOG Committee Opinion No. 340. Mode of term singleton breech delivery. Obstet Gynecol. 2006;108:235-7.

16. Liu S, Liston RM, Joseph KS, Heaman M, Sauve R, Kramer MS. Maternal mortality and severe morbidity associated with low-risk planned cesarean delivery versus planned vaginal delivery at term.
CMAJ. 2007;176:455-60.

17. Rortveit G, DaltveitAK, Hannestad YS, Hunskaar S. Urinary incontinence after vaginal delivery or cesarean section. N Engl J Med. 2003;348:9007.

18. Leijonhufvud $\AA$, Lundholm C, Cnattingius S. Risks of stress urinary incontinence and pelvic organ prolapse surgery in relation to mode of childbirth. Am J Obstet Gynecol. 2011;204:70e1-7.

19. Vistad I, Cvancarova M, Hustad BL, Henriksen T. Vaginal breech delivery: results of a prospective registration study. BMC Pregnancy Childbirth. 2013;13:153-9.

20. Hannah ME, Whyte H, Hannah WJ, Hewson S, Amankwah K, Cheng $\mathrm{M}$, et al. Maternal outcomes at 2 years after planned cesarean section versus planned vaginal birth for breech presentation at term: The international randomized Term Breech Trial. Am J Obstet Gynecol. 2004;191:917-27.

21. Michel S, Drain A, Closset E, Deruelle P, Ego A, Subtil D. Evaluation of a decision protocol for type of delivery of infants in breech presentation at term. Eur J Obstet Gynecol Reprod Biol. 2011;158:194-8. 